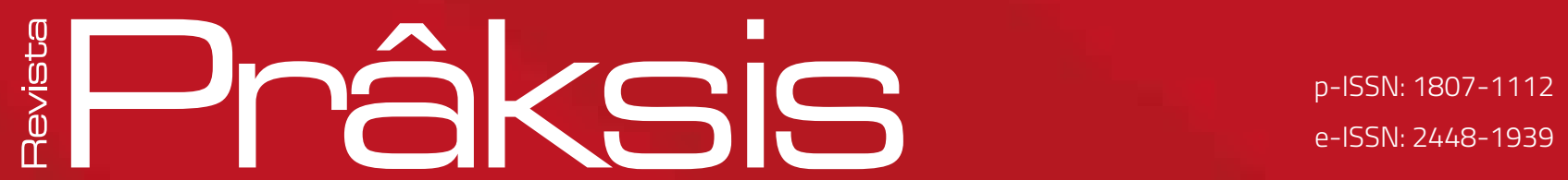

Recebido em: 18 de setembro de 2018 Aprovado em: 20 de dezembro de 2018 Sistema de Avaliação: Double Blind Review RPR |a. 16 |n. 1 | p. 07-31|jan./abr. 2019 DOI: https://doi.org/10.25112/rpr.v1i0.1740

\title{
PRENSA Y POLÍTICA AFRO URUGUAYA: NUESTRA RAZA Y EL PARTIDO AUTÓCTONO NEGRO - PRIMERA MITAD DEL SIGLO XX
}

AFRO URUGUAYA PRESS AND POLICY: OUR RACE AND THE BLACK AUTÓCTONO PARTY - FIRST HALF OF THE 2OTH CENTURY

\section{Eduardo R. Palermo}

Doctorado en Historia por la Universidad de Passo Fundo (Passo Fundo/Brasil).

Director del Museo del Patrimonio en la Intendencia Departamental de Rivera (Uruguay).

Profesor en el Centro Regional de Profesores del Norte (Rivera/Uruguay).

E-mail: palermohistoria@gmail.com. 


\section{RESUMEN}

En 1933 se fundó la Revista Nuestra Raza, órgano de prensa afro uruguayo que denunció la situación social de los mismos, marcada hasta mediados del siglo 20 por el analfabetismo, dificultades de acceso laboral, la prostitución de la mujer "negra", la falta de acceso a los trabajos públicos, bajas remuneraciones, negación de los derechos jubilatorios, la vida en zonas suburbanas y muy pobres, la discriminación y el racismo. Fue un portavoz en el combate al fascismo internacional, a las dictaduras, al racismo y aportó a la unidad cultural afro uruguaya, fundando la Casa de la Raza. Entre las acciones más importantes aporto a la creación, en 1936, del Partido Autóctono Negro con el objetivo de obtener un diputado que los representara. En todos los aspectos la revista fue pionera en las acciones de resistencia y acción militante de los afro- uruguayos.

Palabras-clave: Prensa afro uruguaya. Nuestra Raza. Partido Autóctono Negro.

\section{ABSTRACT}

In 1933, the magazine Nuestra Raza, an Afro-Uruguayan press body, was denounced, denouncing the social situation of the same, marked until the middle of the 20th century by illiteracy, labor access difficulties, the prostitution of "black" women, the lack of access to public works, low wages, denial of pension rights, life in suburban and very poor areas, discrimination and racism. He was a spokesman in the fight against international fascism, dictatorships, racism and contributed to the Afro-Uruguayan cultural unity, founding the Casa de la Raza. Among the most important actions contributed to the creation, in 1936, of the Partido Autoctono Negro (Black Autochthonous Party) with the aim of obtaining a deputy to represent them. In all aspects, the magazine pioneered the actions of resistance and militant action of Afro-Uruguayans.

Keywords: Uruguayan afro press. Our Race. Black Autochthonous Party. 


\section{INTRODUCCIÓN}

En 1877, José Pedro Varela, promovió una reforma educativa que universalizó la enseñanza primaria en el Uruguay. En 1878 el gobierno creó la Escuela de Artes y Oficios para la formación práctica de trabajadores en diferentes tareas. El impacto de la primera fue muy importante en las zonas rurales y permitió el acceso de los afrodescendientes a la educación, el de la segunda lo fue a nivel de Montevideo. Con el gobierno de Batlle y Ordoñez (1903-1907 y 1911-1915) se profundizaron las medidas democratizadoras de la sociedad, surgiendo nuevas posibilidades educativas y leyes laborales que defendían los intereses de los trabajadores. El periódico afro La Regeneración afirmaba en 1885 que el colectivo ya no se encontraba en materia educativa como sus antepasados y que la educación gratuita [y obligatoria para todos] había mejorado su condición social, la Escuela de Artes y oficios "permitía capacitarse en herrería, construcción naval, reparaciones y mecánica" por lo cual muchos padres mandaban a sus hijos a estudiar: "probando que de lo que se trata es formar ciudadanos laboriosos y honrados" (ANDREWS, 2011, p. 64)

Sin embargo, el núcleo afrodescendiente, habiendo obtenido libertad y reconocimiento legal como ciudadanos, aún se encontraba limitado en la práctica, pues siguieron afectados por sus condiciones previas de origen, pobreza, discriminación, dificultades de acceso a empleos bien remunerados.

Dentro de los afros uruguayos, debemos distinguir dos sectores, a nuestro juicio diferenciado, el de los afro-montevideanos y los afro-fronterizos. En el caso de los primeros los espacios de libertad y educación fueron sensiblemente mayores y mejores y ello se expresó en oportunidades concretas a diversos niveles. Por ejemplo, en el acceso a estudios universitarios, técnicos, posibilidades de agremiación, formación de barrios y participación en sindicatos, todo ello no exento de discriminación. Seguramente en materia deportiva y en el carnaval, con el candombe y las comparsas, así como en el tango y otras expresiones musicales, la cultura afro montevideana se visibilizo y conto con cierto reconocimiento público.

En el caso de los afros fronterizos y en general en todo el Norte del país y fronteras con Brasil, su condición de ex esclavizados siguió pesando fuertemente en su proyección social. En su mayoría siguieron en las zonas rurales en la condición de servidumbre, trabajando por el techo y la comida, sin derechos jubilatorios. El ejército se transformó en el principal empleador público y todos los trabajos brazales continuaron siendo realizados por los afrodescendientes. El caso de las incorporaciones al ejército, la leva de "negros", a pesar de contradecir los derechos, fue practicada por los gobiernos de turno hasta finales del siglo XIX, siendo denunciada como un abuso que provocaba la fuga de los jóvenes hacia Buenos Aires (ANDREWS, 2011, p. 56). En las zonas rurales la situación fue diferente pues muchas veces eran reclutados forzadamente en las propias estancias y no había posibilidades de huir, de esa forma el ejército uruguayo fue durante mucho tiempo afrodescendiente y aún hoy en las zonas de frontera, es su principal componente. 
El novecientos uruguayo estuvo marcado por una emigración europea muy importante que cambió los perfiles culturales coloniales, instaurándose en la campaña la imagen del paisano de bombacha, boina y alpargatas, agricultor o pequeño propietario cuyo trabajo era esencialmente familiar; en las ciudades la multiplicación de la clase obrera con costumbres e ideas diferentes. En ese contexto los afrodescendientes debieron competir, en forma desigual, por los puestos de trabajo. En unas cuantas generaciones los inmigrantes europeos constituyeron empresas, fortuna, conformaron la clase media uruguaya, ocuparon cargos políticos, obtuvieron títulos universitarios y la mayoría de los empleos públicos en una sociedad fuertemente estatista. La cultura y la sociedad uruguaya se autoproclamaba de raíz "blanca" y europea, "la Suiza de América". La población afro uruguaya quedo relegada en todos los aspectos, generándose una invisibilidad de la "negritud", excepto en algunas áreas que socialmente aparecen como "naturales para el negro", los deportes, la música, el carnaval y los trabajos brazales (recolección de residuos, peón, lavandera, doméstica).

En una carta dirigida en 1892 por el joven afro Francisco Rondeau, al presidente del país Julio Herrera y Obes, reclamando no poder acceder a un empleo público, recibió la siguiente respuesta, si hay un país "donde la democracia [es] una realidad práctica es el nuestro, donde nadie pregunta al hombre, de donde sale ni donde viene, sino lo que vale y adónde va", para afirmar más adelante, "el color negro solo es caso de vergüenza y de desprecio cuando se refleja en la conciencia. Trate usted de tenerla siempre blanca y pura y no le importe el color negro de su cara" (ANDREWS, 2011, p. 66)

Romero Rodríguez (2006) define a esa situación como "racismo a la uruguaya", sutil pero incisiva. Como ejemplo de ello, en 1931, el gobierno de Gabriel Terra (1931-1934) ordenaba a los Jefes de Policía el cese de la discriminación racial, obligando a contratar afrodescendientes como funcionarios policiales, condición restringida hasta entonces. En marzo de 1943 el jefe de policía de Montevideo, Juan Carlos Gómez Folle, desconoce la situación y llegó a la destitución de los policías "negros", por ser "indecorosa".

\section{LOS PRIMEROS MEDIOS DE PRENSA}

El primer periódico editado por afrodescendientes en Uruguay, se denominó La Conservación (1872). No fue una tarea sencilla; la posibilidad de dar su opinión requería contar con un lugar propio donde poder expresarse públicamente. El colectivo afro sufría condicionamientos, no siempre de forma expresa pero sí de hecho, que coartaban sus posibilidades de libre expresión intelectual.

Con La Conservación hubo una voz de protesta contra la exclusión y la discriminación, cumpliendo un papel importante en la promoción de los derechos de dicho colectivo. Su lenguaje fue directo y sin medias tintas, responsabilizando a los partidos políticos ("blancos y colorados") por usarlos como "carne 
de cañón" y no otorgarles, en función de su participación en múltiples guerras, los derechos igualitarios que les correspondían por: "derecho [a] los afro-uruguayos a gozar de plenos derechos civiles y políticos, así como a la igualdad. No ejercer tales derechos sería una traición al sacrificio de sus padres y abuelos" (SCURO SOMMA, 2008, p. 78).

Paralelamente, al principio de la década del 1870 habían surgido al menos dos "clubes de negros", vinculados al Partido Colorado: el Club Defensa y el Club Igualdad y Fraternidad, presidido por José María Rodríguez y del cual surgiría el periódico La Conservación. Su primer número se publicó el 4 de agosto de 1872, y el último registrado el 24 de noviembre de dicho año, siendo sus redactores Marcos Padin, Agustín García y Andrés Seco. De ese primer número, entre los artículos que hacen referencia a los afrodescendientes, extractamos parte del titulado "Una ojeada sobre nuestra Sociedad", donde se hace un fuerte llamado a la unidad:

\begin{abstract}
Ya era tiempo que nos hiciéramos conocer, para que vean varios que nos tienen en nada, que también en nosotros existen hombres capaces y de convicción [...] Hagámosle comprender a esos hombres, que aún hoy nos miran en menoscabo que somos tan iguales a ellos, que aunque ostenta nuestra faz un color oscuro, tenemos el corazón que late como el mejor, y abrigamos una misma conciencia. Hagámosle ver, que hoy no somos los hombres de antes, porque estamos completamente desengañados, porque se nos presenta un porvenir muy halagüeño; si nos sabemos conducir, así que nosotros debemos propender a ser unidos, debemos propender a que se concluya esa tremenda desunión por la que actualmente atravesamos, que parece fuéramos unos incorregibles; siempre entregados a la labor maldita de esa misma desunión"11 (SCURO SOMMA, 2008, p. 84).
\end{abstract}

Para agregar en otro editorial con meridiana claridad: "Los hombres blancos, serán siempre los mismos, por más que ellos quieran disimular su despego a nuestra raza aparentando sentimientos liberales y democráticos" (RODRÍGUEZ, 2006, p. 60). Este periódico proclamó e impulso la candidatura del afro montevideano José María Rodríguez al parlamento nacional dentro de una lista del Partido Colorado, pero unos meses antes, los "colorados" retiraron su apoyo con un argumento racista: "que diría el extranjero al ver un negro sentado en las bancas representativas". La reacción fue inmediata, desde las páginas de $L a$ Conservación se dijo: "Los hombres blancos [...] son enemigos de nuestra raza", proclamando la necesidad de conquistar "nuestros derechos [...] somos ciudadanos libres", dejando de lado a los partidos blanco y colorado (ANDREWS, 2011, p. 60).

En un nuevo editorial con mucha fuerza reivindicatoria, decía:

${ }^{1}$ La Conservación, № 1, Montevideo, 4 de agosto de 1872, pp. 1 y 2. Citado en: SCURO SOMMA, Lucía (coordinadora): 2008, p. 84. 
Reconozcámonos todos y presentémonos ante el cuerpo legislativo a reclamar los derechos que tan escandalosamente nos han usurpado. Con identidad propia, a través de nuestro conocimiento y cultura [...] No miremos más los colores políticos por los que nos hemos sacrificado sin obtener por nuestros sacrificios la mínima recompensa. Levántate raza, basta de ser sumisa en necias teorías, basta de puerilidades, trabajemos por nosotros mismos en el goce de nuestros derechos (RODRÍGUEZ, 2006, p. 62).

En la misma década del setenta surgieron otras publicaciones: El Progresismo (1873), La Regeneración y El Porvenir, El Sol (1880), todos de corta duración. La Regeneración inició su segunda época, el 14 de diciembre de 1884 hasta el 10 de mayo de 1885, luego aparecieron El Periódico (1889) y La Propaganda (1893-1895). El Periódico fue un semanario que se definía como "Órgano de las Clases Obreras" y sus propietarios fueron los afro uruguayos Felipe Pereyra e Hipólito Martínez. En 1901 se publicó Ecos del Porvenir, proclamándose "periódico de la raza de color" fundado por Guillermo Céspedes y Brígido Anaya, del que salieron solo cuatro números.

A principios del siglo XX se destacaron los periódicos La Propaganda (1911) y La Verdad, (1911-1914) que se proclamaban legítimos representantes del colectivo afro. En el primero integraba la redacción Marcelino Bottaro, destacado periodista e intelectual afro cuyos editoriales proclamaban la unidad de la colectividad como eje central. Reclamaba una militancia efectiva en los temas de fondo que afectaban a los afro uruguayos (desempleo, discriminación, racismo, bajos salarios entre otros) a la vez que criticaba a los clubes sociales afros por su "futilidad de acciones", cuyos intereses se situaban en los bailes y organización de fiestas. Este periódico, de la mano de Bottaro, estuvo ideológicamente alineado con el pensador T. W. Booker ${ }^{2}$ y desde sus páginas según Romero (2006, p. 87), se observaba una tendencia elitista, el gusto por el arte rococó y la literatura de la época.

Al frente de La Verdad estaban Felipe Mansilla, Victoriano Rivero y Lino Suarez Peña, probablemente el intelectual afro uruguayo más destacado de la primera mitad del siglo XX. El periódico presentaba varias secciones permanentes: notas sociales, femeninas, sección poética. Según Pereda Valdés (1965:206) en esta publicación se percibe una mayor comprensión "de la situación de la raza de color en medio de la progresista sociedad que vive el desarrollo de Montevideo en los primeros veinte años del siglo XX". La propuesta que perseguía La Verdad se expresaba en el número 9 del 5 de diciembre de 1911:

\footnotetext{
2 Educador y líder de la comunidad afro estadounidense. Fue liberado de la esclavitud en su infância. Creía que la educación era la clave para que la "comunidad negra" ascendiese en la estructura económico-social de los Estados Unidos. Se convirtió en su líder y portavoz a escala nacional. Fue el primer afro americano invitado con honores a la Casa Blanca.
} 
La Verdad ha venido a poner de manifiesto las necesidades de que adolece nuestra colectividad, a proclamar la necesidad de la unión, el esfuerzo común para la realización de nuestra obra social. No comulgamos en los altares de la tolerancia: fustigar lo malo ese es nuestro lema.

\section{REVISTA NUESTRA RAZA: 1917 - 1948}

La prensa afro uruguaya alcanzó con la edición de Nuestra Raza, especialmente en su segunda época el punto más descollante desde lo periodístico, ideológico, político y cultural.

Nuestra Raza se inició en San Carlos de Maldonado en marzo de 1917, por iniciativa de María Esperanza y Ventura Barrios, llegó a tener 250 suscritores, pero cesó su actividad con el número correspondiente al 31 de diciembre de 1917. A mediados de 1933 reaparece en Montevideo por iniciativa de Ventura Barrios, Pilar E. Barrios y Elemo Cabral que son sus redactores terminando en 1948 su publicación.

Este fortalecimiento del activismo afro, que concluyó con la creación de un partido político, coincide también con el periodo histórico del auge del fascismo, la dictadura de Gabriel Terra y la Segunda Guerra Mundial. El movimiento afro-uruguayo de los años 30 floreció con la resistencia al fascismo. ${ }^{3}$

El historiador estadounidense Reid Andrews, $(2015$, p. 7) afirma que Nuestra Raza 'fue la principal manifestación en el Uruguay del movimiento cultural New Negro que atravesó el Atlántico durante las décadas del 20 y del 30". Fue redactada por un conjunto de escritores, periodistas e intelectuales afrodescendientes, con una importante participación femenina. Adoptó una postura de frente popular, defensa del colectivo afro y de oposición militante frente al fascismo, manteniéndola incluso durante la Segunda Guerra Mundial. Según Andrews (2015, p. 7) "el periódico fue vigorosamente internacionalista en su orientación, prestando cercana solicitud a los acontecimientos y movimientos culturales, políticos y literarios en Europa, Norteamérica y África". Reid Andrews (2011) sostiene que la actividad periodística afro uruguaya (esencialmente montevideana) fue por lejos la más activa de Latinoamérica y, en términos absolutos, la segunda más grande después de Brasil.

Entre los fundadores y colaboradores de la revista se encontraban Pilar Barrios (1889-1974), escritor, poeta y sus hermanos, María Esperanza y Ventura (tipógrafo); Alberto Britos (procurados, escritor e investigador sobre folklore afro latinoamericano); Carlos Cardozo Ferreira (obrero gráfico, escritor y poeta); Roberto Suárez (obrero, poeta); Elemo Cabral (portero, escritor) y sus hijos Iris y Gilberto (funcionario público); Tulio y Sandalio Gutiérrez; Feliciano A. Barrios; Maruja Pereira (empleada doméstica,

\footnotetext{
${ }^{3}$ CULTELLI, Martín Delgado. El Movimiento Afro-uruguayo de los años 30. Disponible em: <https://www.laizquier-
} dadiario.com.uy/El-Movimiento-Afro-uruguayo-de-los-anos-30>. Consultad en: 1 ago. 2018. 
fundadora de la asociación de empleadas domésticas de Montevideo, esposa de Pilar Barrios); Selva Escalada; Isabelino Gares (dramaturgo); Marcelino Bottaro (intelectual, escritor); Santos Zapata (poeta); Mario Rufino Méndez (dibujante, caricaturista), Ildefonso Pereda Valdez (abogado, escritor e historiador) entre otros afro uruguayos, de gran protagonismo en la redacción, impresión y distribución del periódico.

María Cristina Burgueño (2015, p. 11) analiza el perfil del equipo de redacción de la revista:

\begin{abstract}
Este grupo estaba constituido por hombres y mujeres que en su mayoría trabajaban como obreros y empleados en oficios y puestos humildes a los cuales quitaron tiempo para obtener su cultura. Estos periodistas, que celebraron en las páginas de la revista el ascenso al rango de auxiliar segundo en alguna oficina pública, o la obtención de un diploma de Corte y confección de algunos integrantes de la colectividad afrodescendiente, fueron ellos mismos, en su mayoría, porteros — como Elemo Cabral en el Museo Histórico Nacional— o domésticas —como Maruja Pereira de Barrios".
\end{abstract}

Es muy importante resaltar que todas las publicaciones periódicas afro fueron sustentadas con el aporte de sus miembros, restando a su sustento personal o familiar, como se atestigua varias veces, en función de una "tarea superior" que hacía a la dignidad y nobleza del colectivo afro.

Desde la perspectiva política y social, en Nuestra Raza resaltó el cuño marxista de los artículos, no llegando a seguir una línea de internacionalismo proletario, pero con una fuerte inspiración en esa corriente. Los intelectuales afro latinoamericanos estaban naturalmente influenciados por dicha corriente de pensamiento que se posicionaba como anti imperialista, anti colonialista y por la etapa histórica de la publicación, como anti fascista y allí también recogían las aspiraciones de un colectivo fuertemente sumergido económicamente, discriminado y sufriendo los efectos de un racismo estructural, convenientemente disfrazado de republicano-democrático, un racismo "sutil" como ya manifestado.

Burgueño (2015, p. 14) afirma que la línea marxista provenía de la influencia de Salvador Beterbide. Este pensador, activista y abogado afro-uruguayo Salvador Beterbide (1903-1936) fue el principal intelectual del pensamiento y activismo afro-uruguayo.

Había nacido en el seno de una familia humilde en Melo, Cerro Largo. Realizó la carrera de abogacía en la Universidad de la República, recibiéndose en 1925 con 22 años, siendo el graduado más joven de su generación. En su vida tuvo una notable influencia Grauert, como mencionado, con quién fue compañero de clase durante la carrera universitaria, amigos personales y compañeros partidarios. Grauert fundó el Movimiento Avanzar, dentro del Partido Colorado, grupo progresista colorado, al que se integró Beterbide. El 31 marzo de 1933, el presidente Gabriel Terra, "Colorado", disuelve las cámaras comenzando una etapa de dictadura. Grauert ejerció una férrea oposición a la misma. En octubre de ese año fue emboscado por la policía a la salida de un comicio falleciendo el 26 de octubre (PALERMO, 2016). Esto definió a Beterbide a 
alejarse del Movimiento Avanzar, buscando generar un espacio político propio en el marco de la comunidad afro uruguaya y con una definición ideológica muy próxima del socialismo (GASCUE, 1988, p. 5).

Su actividad periodística comenzó con la fundación del periódico La Vanguardia, cuyo primer número se publicó el 15 de enero de 1928. Lo acompañaba en la redacción Isabelino Gares, destacado intelectual y activista, considerado uno de los mejores escritores de la época. Desde este medio introduce las ideas socialistas e internacionalistas en la comunidad afro, bregando por la creación de un partido político que defendiera los intereses de "la Raza" (RODRÍGUEZ, 2006, p. 99). Posteriormente fue co-fundador de Nuestra Raza en su segunda época (1933-1948). Durante este período Beterbide ejerció como abogado de oficio en la defensa de los afro uruguayos, transformándose en un activo promotor de la causa de los derechos humanos, el ejercicio de la solidaridad internacional con todos los afrodescendientes y el combate contra el racismo (PALERMO, 2016).

En su segunda época, Nuestra Raza editó su primer número el 25 de agosto de 1933, a pocos meses del golpe de Estado de Gabriel Terra y en el día que se recordaba la independencia del país proclamada en 1825 y entre cuyas leyes fundacionales se integraba la ley de libertad de vientres y la supresión del tráfico esclavista. Fecha significativa la elegida para enviar un mensaje, no ocasional a la colectividad.

La publicación se vendía puerta a puerta en los conventillos, edificaciones donde se alojaban fundamentalmente afrodescendientes e inmigrantes, de precarias condiciones generales donde se vivía como una gran familia. Los conventillos se transformaron en reductos culturales afros generando expresiones musicales como las comparsas. En ese entorno la revista Nuestra Raza fue la más alta expresión cultural y colectiva, la caja de resonancia de la comunidad afro uruguaya en defensa de los temas nacionales e internacionales que afectaran a los afrodescendientes, a la libertad, los derechos humanos y contra toda forma de discriminación.

En su primer número, el editorial escrito por Pilar Barrios, manifestaba: "la honda crisis agudizada por los complejos problemas sociales, levanta el clamor general de los humildes, creemos que llegamos en la hora propicia en que es necesaria la colaboración de todos para dar solución a esos problemas" (RODRIGUEZ, 2006, p. 109).

La edición de la revista fue un gran catalizador de los esfuerzos realizados hacia una unidad coherente del colectivo afro. La predica de Marcelino Bottaro desde La Propaganda de crear una "Casa de la Raza" fue concretada con el apoyo de todo el equipo de la revista. Coadyuvó a ello los artículos de Lino Suárez Peña desde el periódico La Verdad, reivindicando el papel central de los afro uruguayos en el desarrollo histórico y construcción del país y finalmente, al impulso de Salvador Beterbide, la necesaria articulación de "lo afro" en el movimiento social y obrero uruguayo e internacional, vinculando los reclamos de la 
colectividad uruguaya con los grandes temas del racismo y la explotación de los trabajadores a nivel mundial. El escenario internacional del nazi-fascismo dio un impulso a la concientización de los grandes temas, especialmente cuando la década del 30 en Uruguay mostraba, a través de la dictadura de Terra, el desembarque de esas ideas en el país.

La creación de la "Casa de la raza" era un proyecto que Bottaro impulsaba desde la década de 1920, infructuosamente, por la oposición de los "Centros Recreativos" ya mencionados. En la creación de esta institución se definía como objetivo central:

[...] fomentar en alto grado la unión social, elevar el nivel cultural e intelectual, realizando un intercambio literario - periodístico con los conrazáneos de otros países. [...] realizar toda clase de actos públicos y culturales. Se realizarán tertulias entre los socios y familias de estos. [...] Se alquilará para ello una casa para sede social, una biblioteca, una sala de lectura, un salón-bar con toda clase de juegos. [...] Al año de fundado este club, dará en sus salones, clase de instrucción primaria y secundaria gratuitamente a todos los conrazáneos que la soliciten (RODRÍGUEZ, 2006, p. 114).

El proyecto claramente cumplía con los designios de los colaboradores de la revista, a la postre integrantes de la primera Comisión Directiva en junio de 1934, combinando aspectos culturales y educativos centrales a la problemática afro, pero no dejando de lado los aspectos recreativos, superando así la propuesta de los otros clubes existentes que solo atendían dichos aspectos y que en opinión de Nuestra Raza contribuían muy poco a superar las deficiencias existentes.

La propuesta fue más lejos, pues se estableció como cometido del club realizar un relevamiento de los analfabetos, en este caso afro- montevideanos, promoviendo su alfabetización y en caso de ser menores incentivando su concurrencia a las escuelas públicas más cercanas de sus hogares. Lamentablemente su vida fue efímera en función de la indiferencia de la mayoría, de la imposibilidad económica de sustentar el proyecto y en el área educativa de las dificultades de traslados hacia y desde el local. No puede olvidarse que los mismos fondos que sustentaban la revista terminaron soportando la Casa de la Raza. En cambio, durante esta década del 30 y en la siguiente los clubes meramente recreativos aumentaron su número. Una buena definición de la separación existente entre este grupo intelectual, denominado como "elite negra" por Romero Rodríguez (2006) de los sectores populares, la distancia entre el impacto del discurso y la realidad social afro uruguaya.

Desde la revista también se impulsaron acciones concretas con respecto a la diáspora africana. La formación del "Comité Scottsboro de Uruguay" fue un jalón de importancia pues por primera vez la sociedad montevideana observaba la acción de la comunidad afro fuera de los ámbitos de discriminación a los que estaban confinados: trabajo, recreación, carnaval. 
El caso de Scottboro en el estado de Alabama, tuvo repercusión internacional por la prisión y sentencia a muerte de nueve jóvenes afros acusados de violar dos mujeres "blancas", delito que no cometieron, en 1931. En el editorial de mayo de 1934 se afirmaba:

el comité Scottsboro, formado por hombres de todas las tendencias con el levantado y humano propósito de unir su voz al coro general de protesta [...] Representada en millares de trabajadores e intelectuales de la talla de Máximo Gorki, Albert Einstein, Henry Barbusse, Wells y muchos otros y de quienes habían logrado detener por un instante la mano que quiere tronchar la vida de 9 hombres inocentes, fraguado en la monstruosidad de un proceso, un justificativo que sólo existe en un morboso odio de raza y clase (NUESTRA RAZA, N. ${ }^{\circ} 10$, mayo de 1934).

Posteriormente se publicaron noticias sobre el caso donde se manifestaba que las propias mujeres, supuestamente violadas, habían reconocido haber sido sobornadas para declarar eso y en eso momento eran militantes activas del movimiento en pro de la liberación de los jóvenes, lo que transformaba el caso en una clara acción racista promovida activamente por el Ku Klux Klan.

Otro aspecto destacado del accionar internacional de la revista fue su defensa de la libertad de Etiopía (Abisinia en 1935) contra los ataques de la Italia fascista

Burgueño (2015, p. 15) señala que en los artículos publicados predominaba la idea que el fascismo y el racismo se vinculaban a la explotación de la clase obrera y el colonialismo. En el manifiesto del Comité de la Raza Negra en Contra de la Guerra y el Fascismo, se definía al fascismo como "el brazo armado de los imperialistas, camarillas de traficantes de la guerra", afirmando que la guerra sobre el único país independiente de África, Etiopía, se impulsó luego de reducir a "esclavitud a la clase obrera italiana", de "destruir las organizaciones sindicales y todas las libertades del pueblo".

En diciembre de 1935 se creó a impulso de la revista el comité antes mencionado contando con el apoyo del colectivo afro de Montevideo, Cerro Largo y Rocha entre otros lugares del país. Desde el comité se proclamaba la defensa del derecho de auto determinación de los pueblos y el apoyo a toda organización social, sindical, cultural y política que luche contra el fascismo internacional, en la defensa del pueblo etíope, por su libertad y contra la guerra (NUESTRA RAZA, N.²9, diciembre 1935).

Paralelamente se creó dentro del comité una "sección femenina" demostrando de esa forma el papel importante que la mujer afro cumplió históricamente dentro del colectivo, como es costumbre dentro de la tradición socio-cultural africana de base matriarcal. En junio de 1936, desde la revista se da cuenta de la participación de Iris María Cabral y Maruja Pereyra en el primer Congreso Nacional de Mujeres, organizado en función del repudio al fascismo y la guerra, integrado ciudadanas de todas las extracciones políticas y sociales. Pero no fue la temática bélica la única tratada, en la medida que la participación femenina estaba 
restringida, no obstante, desde la reforma electoral de 1919 se había concedido su derecho al sufragio, que recién se hizo efectivo en las elecciones libres de 1938 con una alta participación. Iris Cabral defendió en esa instancia la necesidad de la sindicalización de las domésticas, históricamente afrodescendientes, y la conquista de leyes que les otorguen protección social. Cabe recordar que la mayoría no tenían derechos jubilatorios y a lo sumo obtenían una pensión que apenas les permitía sobrevivir luego de largos años de servicio.

\section{EL PARTIDO AUTÓCTONO NEGRO (PAN): 1936 - 1944}

La población uruguaya en la década del 30 podría estimarse en el entorno de casi dos millones de habitantes, de los cuáles Pereda Valdez consideraba que un 7 \% eran afrodescendientes. Esta minoría étnica mayoritaria en algunas partes del territorio, como el Norte del país y la frontera con Brasil, poseía una condición común, la pobreza, llegando a la pobreza extrema en muchos casos, la falta de oportunidades laborales, especialmente en la función pública, lo cual era particularmente grave en un país donde el funcionariado dependiente del Estado crecía en forma muy rápida. La única excepción de trabajo público radicaba en formar parte del ejército, donde también tenían vetado el acceso a ser oficiales de carrera. Además, estaban sometidos a la discriminación laboral por pertenencia étnica ya que se les reserva los empleos peor pagos o rechazados por otros trabajadores. En el caso de las mujeres era más grave pues sufrían la discriminación por ser mujeres, pobres y afrodescendientes. Mayoritariamente su empleo era el de domésticas, lavanderas y planchadoras. Muy pocas se desempeñaban como obreras. En las zonas rurales el papel de cocineras era predominante, casi exclusivo junto al de ama de leche. En la educación, a pesar de ser pública, gratuita y obligatoria, sufrían la discriminación de oportunidades por las necesidades de ingresar tempranamente al mercado laboral o ayudar en el sustento de sus familias.

De tal forma el panorama era deficiente y por ello las acciones de resistencia y valorización como la prensa afro, los clubes sociales y la búsqueda de dignidad social, llevaron al esfuerzo de generar un espacio político propio fuera del ámbito de los partidos históricos (blancos y colorados).

No es casualidad que las pretensiones políticas, que ya venían desde finales del siglo XIX, propuestas de La Conservación en 1872 como mencionado, maduraran en este período y con el impulso de Nuestra Raza. La dictadura terrista, el avance del nazi-fascismo en Europa y las expresiones similares en el Río de la Plata, operaron como una motivación extra en el pensamiento de quienes impulsaban la idea.

La propuesta política y filosófica del PAN era claramente étnica, pero a la vez profundamente integracionista, veamos la cita que hace al respecto Gascue $(2,1988$, p. 48), extraída del manifiesto político del mismo de fecha 23 de mayo de 1936: 
Bien es cierto que legal y constitucionalmente la igualdad de todos los ciudadanos está ampliamente reconocida [...] aparecemos como perfectamente respetados [hace referencia al colectivo afro] en la aplicación de aquellas normas directrices. Pero si detenemos nuestro espíritu crítico, si tratamos de fijar nuestra verdad verdadera sobre esa aparente situación de igualdad, veremos [...] que aún el prejuicio está lejos de desaparecer. Cualquiera de nosotros sabe perfectamente que en más de cien casos, el ascenso de un empleado o el nombramiento de un funcionario, no ha dependido por cierto de la mayor o menor idoneidad [...] sino de la mayor o menor pigmentación [de la piel] de aquel o de esta.

Afirmando a continuación el objetivo supremo perseguido por el colectivo político afro: "en favor de los desheredados contra los opulentos, en favor de los oprimidos contra los opresores, en favor de la conquista de una verdadera justicia social".

Sin embargo, la formación del PAN se inscribe en un contexto más amplio del movimiento afro latinoamericano, cuyo proceso puede asimilarse a la experiencia brasileña con la formación del partido Frente Negra de la década de 1930.

El día 16 de septiembre 1931 se fundaba el Frente Negro Brasileño (FNB), primer partido afro brasileño, un importante hito histórico y político para el movimiento en dicho país. Este a su vez tiene antecedentes con la formación en São Paulo del Centro Cívico de Palmares, fundado en 1926, cuyo accionar superó los límites de una entidad recreativa desarrollando el tema de la participación política.

EI FNB funcionó en el salón de las clases trabajadoras, en la Casa de Portugal. Allí mantuvo escuela, departamento de asistencia social y jurídica, club de teatro, prensa, promovió conferencias y grandes bailes. Es inevitable recordar las similitudes con la Casa de la Raza, proyecto impulsado desde los años 20 y creada en Montevideo en 1934, como antes manifestado.

La historiadora Beatriz Loner (1999, II) en su análisis sobre la clase operaria de Pelotas, importante centro esclavista del Sur de Brasil, manifestaba que en la década de 1930 los centros sociales que nucleaban a los afro-pelotenses adoptaron un importante giro en sus organizaciones, dejando parcialmente de lado los centros recreativos, deportivos y carnavalescos para adoptar posturas más políticas que llevaron a la creación del Frente Negro Pelotense (FNP) a impulso de un cambio en sus principales órganos periodísticos como ser A Alvorada, A Vanguarda y A Cruzada. A Alvorada (1907-1960) fue el más destacado siendo su línea editorial la valorización del colectivo afro defendiendo su elevación cultural y social como grupo.

En 1933 surgió la principal asociación política afro, Frente Negra Pelotense, (FNP) que significó un sustancial avance en el sentido de la afirmación del colectivo negro como un grupo diferenciado y organizado en la ciudad. Sus representantes, a similitud del colectivo afro-uruguayo, luchaban contra la 
discriminación racial y buscaban por medio de la educación y la capacitación mejorar el status social del colectivo (LONER, 2).

Otra similitud con el proceso uruguayo de la misma época, lo cual nos revela una preocupación regional y continental por estos temas, dicho de otra manera en todos los países los colectivos afros pos-abolición disponían de un claro diagnóstico de situación. En el caso de las relaciones entre Pelotas y el territorio uruguayo, es importante señalar los extensos vínculos históricos existentes entre las poblaciones de frontera Uruguay-Brasil desde el siglo XIX, así como con Montevideo, principal puerto platense que vinculaba el Brasil Meridional con el Río de la Plata y Europa (PALERMO, 2013).

Loner (1999, 1, II, p. 401) afirmaba que a través de la FNP:

A etnia negra deu um salto qualitativo em sua luta pela afirmação racial e integração social [...] a partir da constatação da necessidade de uma entidade aglutinadora na luta contra a discriminação racial. Entre seus objetivos destacavam-se: congregação da etnia, ministrando-lhes ideias, ensinamentos nobres e altruísticos, realizar palestras, conferencias e ações tendentes a elevar o homem negro; organizar bibliotecas e cursos de alfabetização, além de pleitear a admissão de elementos de cor aproveitável nos ginásios.

La FNP estuvo activa escaso tiempo, de 1933 a 1935, enviando representantes al I Congresso Afro Brasileiro, realizado em Recife en 1934. Loner (2) sostenía que la misma:

constituiu-se num primeiro momento claro de politização da luta do negro na cidade contra o preconceito. Muito ligado a esta Frente estava o jornal A Alvorada, com o qual compartilhavam muitos redatores e dirigentes, vários deles de tendência socialista, que depois se apresentariam como candidatos a deputação estadual em 1934 pelo Partido Socialista Proletário do Brasil, cuja nominata estadual, composta de oito nomes, incluía cinco pelotenses e, desses, quatro negros.

También en estos aspectos hay similitudes entre Nuestra Raza, sus objetivos y el PAN, especialmente en el perfil político socialista de los editores del periódico, así como de sus vinculaciones directas con la formación del FNP. Probablemente la principal diferencia radique en el estilo más directo y agudo del lenguaje y las críticas a la sociedad uruguaya y a la oposición al avance del fascismo a nivel internacional, con tapas de la revista que revelaban un estilo militante de corte socialista y claramente antifascista.

Andrews (2011) sostiene que este perfil forma parte de los contactos existentes entre los movimientos afro rioplatenses y los intelectuales, escritores y periodistas afros de Estados Unidos, Europa y el Caribe.

En 1934 en las reuniones del FNP participaban militantes socialistas, comunistas, y sindicalistas, aunque el periódico A Alvorada negaba cualquier filiación partidaria clara con dichos grupos. Ese mismo año, y al igual que en Montevideo, se formó una "Legião Feminina", demostrando de esa forma 
la importancia de la mujer dentro del colectivo afro con un alto protagonismo. No obstante el comité femenino de losafro-montevideanos tuvo un papel militante en la lucha antifascista habida cuenta de la situación política del país inmerso en la dictadura de Gabriel Terra, la proliferación de prensa pro-fascista y el desarrollo de las teorías eugenésicas que valorizaban el origen"blanco" y "puro" de la población discriminando a todas las etnias por sus "escaso valor" cultural y aportes al país.

Otra diferencia importante de Nuestra Raza y el PAN con respecto al FNB radicó en que este, centrado en Sao Paulo y Rio de Janeiro, manifestaban una tendencia monarquista y terminaron apoyando al presidente Getulio Vargas en 1933 y al Estado Novo.

Manifestaba Loner (1999, 1, II, p. 402) citando a Andrews (1998:238) al respecto:

Os paralelos entre a orientação anti-imigrantes da Frente e aquela do movimento integralista são impressionantes, assim como outros pontos em comum entre os dois movimentos. Ambos compartilhavam um grande menosprezo pela democracia liberal e, apesar de sua rejeição das filosofias politicas estrangeiras, uma admiração explicita pelo fascismo europeu.

Su primer presidente, Arlindo Veiga dos Santos, fue patrianovista, es decir, de tendencia monárquica, y aunque siempre afirmó que su posición no interfirió en su papel de frentenegrino, las principales críticas al FNB derivaron de esa posición. En 1937 Vargas clausuró todos los partidos políticos entre ellos el FNB que se diluyó por completo, derivando en organizaciones recreativas y en pro de la educación del colectivo afro.

Un elemento importante señalado por Loner (1999, II, p. 404) es la participación del colectivo afro en las organizaciones sindicales ocupando cargos directivos de destaque dentro de todas las tendencias gremialistas y en diferentes partidos.

En el caso uruguayo la prédica de Nuestra Raza y del PAN acompaño una tendencia internacional favorable a la sindicalización e integración plena dentro del movimiento obrero como parte de la clase trabajadora y explotada por el capitalismo. No obstante, la prensa obrerista del país desde principios del s. XX registra muy pocas instancias de participación activa del colectivo afro y casi no hay mención a su participación entre la dirigencia sindical. Esto llama la atención porque siendo Montevideo el principal centro industrial del país la participación de afrodescendientes, especialmente hombres, era importante como mano de obra especialmente en la condición de peones y ayudantes. Ya la mujer se desempeñaba mayoritariamente como lavandera, cocinera, ama de leche y doméstica por lo cual suponemos no desempeñaba actividad sindical en los años 1930. Fuera de Montevideo, cuarteles y estancias representaron las principales fuentes laborales de la mayoría de afrodescendientes masculinos. 


\section{LA FUNDACIÓN DEL PAN}

Las primeras menciones a la fundación de un Partido Negro aparecen en 1935 y cuentan con el apoyo de Nuestra Raza, a través de un artículo de Sandalio del Puerto. Este militante de la causa afro es definido dentro del colectivo como un hombre de ideas claras y manifiestamente socialista, poseía una empresa de construcción (albañilería) y experiencia en el trabajo político (GASCUE, 2, 1988, p. 51).

El principal impulsor del PAN no obstante había sido Salvador Betervide, como ya manifestamos, un hombre de reconocimiento en el colectivo afro y considerado un intelectual, era el candidato de más prestigio para encabezar la lista a la cámara de diputados por el nuevo partido. Para acceder a una banca por Montevideo se necesitaban por entonces alrededor de 2100 votos, una cifra posible de acuerdo a la cantidad estimada de afrodescendientes, un 7\% aproximadamente de la población total. Dicho de otra manera, se necesitaba el $10 \%$ de los votantes de la colectividad afro para obtener un escaño.

Entre sus fundadores encontramos nombres ya conocidos: Elemo Cabral (1887-1969), Ventura Barrios (1896-1952), Pilar Barrios (1899-1974), Salvador Betervide (1903-1936), Isabelino Gares, Maruja Pereira (esposa de Pilar Barrios), Mario Méndez, Ignacio Suárez Peña, Ceferino Nieres, Sandalio del Puerto, Carmelo Gentile, Aníbal Duarte, Ismael Arribio y Gilberto Cabral.

Un destaque para la mujer afro como integrante de la sociedad que ha debido luchar por lograr su visibilización y obtener sus derechos de manifestar su voluntad política y ejercerla dentro del sistema en puestos públicos y en el parlamento. Para la mujer afrodescendiente la lucha ha sido extremadamente compleja ya que además de su condición de mujer, la mayoría de las veces pobre económicamente, debió luchar para ser respetada y aceptada en su condición.

Ya en las guerras de independencia muchas afrodescendientes participaron activamente en la revolución junto a Artigas, como lanceras: Rita de Carvalho, Rosa Antonia de Moreira, María Clara y Elena Pereira, Dominga Maxa, Damiana Segovia, Josefa Antonia Jiménez, María Viaña y Soledad Cruz, entre muchas otras que la investigación irá revelando. Algo similar ocurrió en Rio Grande do Sul durante el período Farroupilha.

Dispusieron de un papel importante en las Casas de Nación y Cofradías, en el período colonial y emancipador y posteriormente promoviendo Asociaciones Civiles y Culturales, manifestando su pensamiento desde la literatura y el periodismo como María Esperanza Barrios, Clelia Núñez Altamiranda, o Virginia Brindis de Salas quienes marcaron un ideario con el objetivo de incorporar la dimensión étnico racial en las prioridades de las políticas sociales desde principios del siglo XX. Es interesante resaltar que la primera vez que la mujer pudo hacer uso del sufragio en Uruguay y América Latina, fue en 1927 cuando se realizó un plebiscito para determinar si la ciudad de Cerro Chato debería formar parte del 
departamento de Cerro Largo o de Durazno. El mismo se realizó el 3 de junio de 1927 y el primer sufragio correspondió a Clementina Silva, afrodescendiente brasileña de 90 años, constituyéndose en un hito continental. Desde entonces la lucha de las mujeres por obtener un espacio político mayor y conquistar el derecho al voto libre continuó sin desmayos y en 1938 finalmente la mujer ingreso como sufragante libre en las elecciones nacionales y concreto una importante participación en las listas electorales, aún sin disponer de los espacios que le correspondían legítimamente como actor político.

Alba Roballo, conocida como "la negra", fue una política de fuste, combativa, abogada, docente y primer mujer afro elegida para el parlamento nacional como Senadora y Diputada por Montevideo, entre 1958 y 1966, dentro de las listas del Partido Colorado. Posteriormente decepcionada con el accionar político paso a integrar el Partido Socialista y en 1971 figura como una de las fundadoras del Frente Amplio, ocupando el cargo de Senador de la República. Su accionar abrió las puertas a una participación más amplia de la mujer en el sistema político (PALERMO, 2016).

Lamentablemente en la organización de la lista política del PAN para las elecciones de 1938, las mujeres no fueron tenidas en cuenta, sin embargo, su accionar como militantes fue imprescindible para difundir la idea dentro del colectivo afro en todo el país.

EI PAN se planteaba como objetivos centrales de su plataforma política: denunciar la discriminación racial ocupacional, promover la unidad de intereses comunes con los sectores más desposeídos de la sociedad, apoyar todas las iniciativas que favorecieran al país y la obtención de un representante parlamentario de la colectividad. En mayo de 1936 se realiza la primera Asamblea en una sala de la Asociación Fraternidad y pocos días después se aprueba su Manifiesto. En septiembre de ese año fallece Salvador Betervide, candidato del PAN y hombre que había encabezado la iniciativa. Fue un golpe duro e ilevantable para la organización. Igualmente se resolvió continuar con el proyecto, pero el descredito interno mino sus posibilidades. En abril de 1937 comenzó a publicarse el periódico del PAN, siendo su primer redactor Sandalio del Puerto y posteriormente Carmelo Gentile. En julio se crearon dos seccionales del PAN, en Rivera y en Cerro Largo, departamento donde la población afro superaba el 30 \% del total.

Del 5 al 7 de marzo de 1938 tiene lugar su Convención en la cual se define su lista de candidatos a la Cámara de Representantes por el departamento de Montevideo, la misma sería encabezada por Mario Méndez, hombre de prestigio y reconocimiento pero que no estaba completamente convencido de la iniciativa.

Todas estas actividades realizadas contaron con un escaso apoyo del colectivo afro, más allá del entusiasmo y la propaganda desde Nuestra Raza, en las elecciones generales realizadas el 27 de marzo de 1938, el PAN obtuvo 87 votos, un verdadero fracaso. 
El resultado sumió al PAN en una crisis que lo inmovilizó hasta 1941 cuando el presidente Alfredo Baldomir, en el cargo como resultado de un golpe de estado contra Terra, convoca a nuevas elecciones en 1942. Pero el efecto de escaso apoyo recogido en las elecciones anteriores, sumado a las disputas internas por el fracaso determino que el grupo se dividiera en dos fracciones, una encabezada por Mario Méndez y la otra por Ignacio Suárez Peña. El núcleo de la revista Nuestra Raza ya se había separado en 1938. El origen de la división radicó en rivalidades personales reforzadas por la idea de que Méndez no representaba cabalmente los intereses de la colectividad. Ambos grupos se disputaron la posesión del lema ante la Corte Electoral, la cual no se define por ninguna de ellas. En junio de 1942 falleció Mario Méndez, lo cual posibilitó que el PAN se reorganizase, sin embargo, no participó en las elecciones nacionales.

En junio de 1944 su Dirección resuelve disolver el Partido y donar sus pocos bienes a Nuestra Raza. Culminando así el intento de organizar un partido político de neta extracción afrodescendientes como organización política independiente de los partidos existentes.

\section{REFERÊNCIAS}

AA.VV. Cuaderno de Historia No 15. Mario Rufino Mendez y la caricatura política en Nuestra Raza. Montevideo: Biblioteca Nacional, 2015. Prólogo de George Reid Andrews.

ANDREWS, George Reid. Mario Rufino Mendez y la caricatura política en Nuestra Raza. Cuaderno de Historia No 15. Montevideo: Biblioteca Nacional, 2015. Prólogo.

ANDREWS, George Reid. Negros en la nación blanca: historia de los afrouruguayos 1830-2010. Montevideo: Linardi y Risso, 2011.

BURGUEÑO, María Cristina. Mario Rufino Mendez y la caricatura política en Nuestra Raza. Cuaderno de Historia No 15. Montevideo: Biblioteca Nacional, 2015

CULTELLI, Martín Delgado. El Movimiento Afro-uruguayo de los años 30. Disponivel em: <https://www. laizquierdadiario.com.uy/El-Movimiento-Afro-uruguayo-de-los-anos-30. Consultado em 1/08/2018>. GASCUE, Álvaro (1) PAN, una experiencia racial y política. Suplemento "El País Cultural", n. 18, may. 1988, Montevideo. 
GASCUE, Álvaro (2) Un intento de organización política de la raza negra en Uruguay. Revista Hoy es Historia, Montevideo, 1988, a. 5, n. 27, p. 47-54.

LONER, Beatriz .(1) Classe operária: mobilização e organização em Pelotas: 1888-1937. Tesis (doctorado em Sociología) - Porto Alegre, UFRGS, Programa de Pós-graduação. 1999. Vol. II

LONER, Beatriz.(2) A etnia negra em Pelotas.

PALERMO, Eduardo. Vecindad, frontera y esclavitud en el norte uruguayo y sur del Brasil. En: Memorias del Simposio La Ruta del esclavo en el Río de la Plata. Montevideo: UNESCO, 2005. pp. 93-115.

PALERMO, Eduardo. Esclavitud, "criadagem" y discriminación, una tendencia de larga duración en la frontera oriental. En: CLEMENTE, Elvo (Org.). Revista INTEGRAÇAO, Historia, Cultura e Ciencia 2004, Coleçao Cone Sul, v. 5. Porto Alegre: Edi PUCRS, 2006, p. 87-129.

PALERMO, Eduardo. Tierra esclavizada, el norte uruguayo en la primera mitad del siglo XIX. Montevideo: Tierra Adentro, 2013.

PALERMO, Eduardo. Salvador Beterbide, biography. In: KNIGTH; GATES JR (Editors). Dictionary of Caribbean and Afro- Latin American Biography. Oxford University Press, UK. USA, New York: 2016. Vol.1 PEREDA VALDEZ, Ildefonso. El negro en el Uruguay, pasado y presente. Revista del Instituto Histórico y Geográfico, Montevideo, 1965

RODRÍGUEZ, Jorge Romero: Mbundo Malungo a Mundele. Historia del movimiento afrouruguayo y sus alternativas de desarrollo. Montevideo: Rosebud Ediciones, 2006.

SCURO SOMMA, Lucía (Org.): Población afrodescendiente y desigualdades étnico-raciales en Uruguay. Montevideo: PNUD, Uruguay, 2008.

\section{Prensa periódica consultada:}

La Conservación, N. 1, Montevideo, 4 de agosto de 1872. Biblioteca Nacional.

Nuestra Raza. Números citados en el texto. Biblioteca Nacional, Montevideo y Museo del Patrimonio Regional, Rivera. 


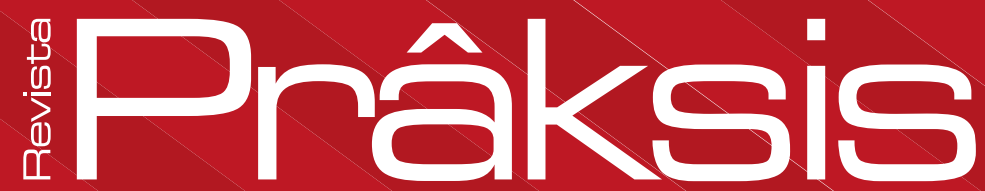

p-ISSN: 1807-1112

e-ISSN: 2448-1939

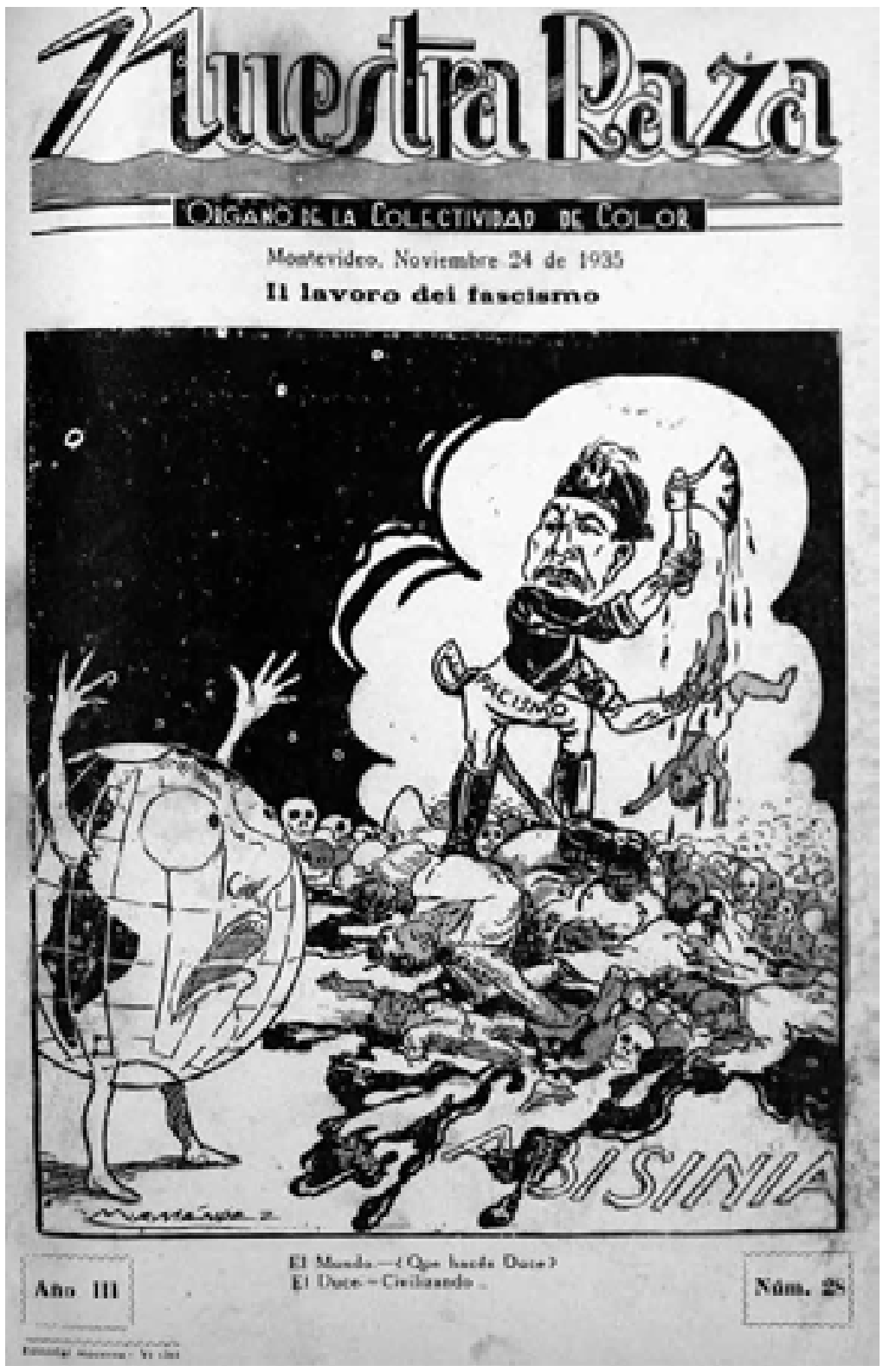

24 de noviembre de 1935, año III, número 28 


\section{A $\quad$ TEESEA EAZA \\ ¡POR LA DEFENSA DE ABISINIA!}

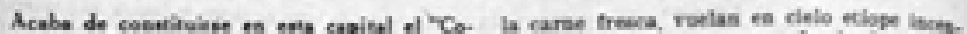
mite de la Rasa Neos contio la guerrs y el

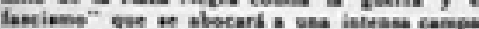

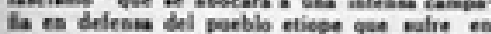

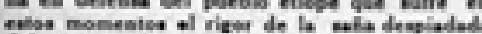
Int strimen lavite.

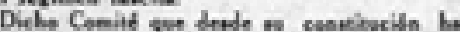

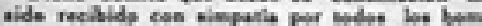

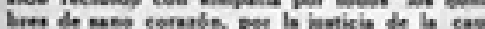

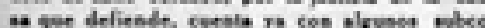

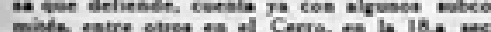
tifin y to los Dotos de Crrro Large y Roche

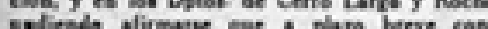

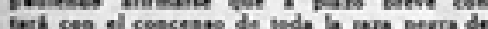
sols,

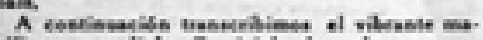
sifiento goe dicho Cemild ha lonndo pars or plicar a le opinide peblica los metiros de 0

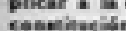

A toda la raza negra del país

A pesar de que noeatra ram hasa bog a vermasecilo indiferente apdica, aste joe preblemas scolales. en esta epertasilot.

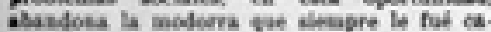

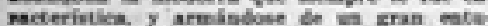

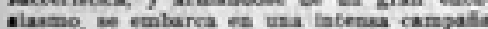
coetra la ruerra y el tascistos, eve en estoe

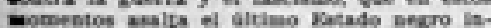
imbradicate.

Bi fancismo italiaso erpoesate be la reac- ila $y$ de la bartarie mis mangrieata sue la.

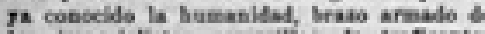
be imperlaliatas camarilias de traficantes

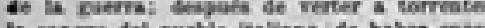

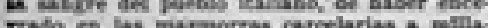

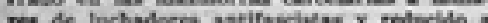

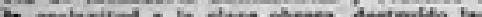

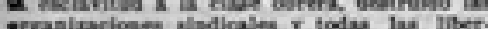

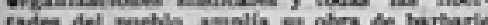
cades del jueblo, anplia sa oblo do tartarie

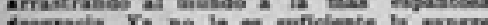

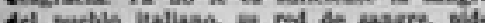

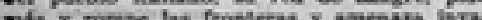

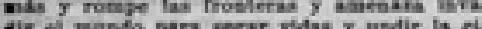

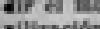

Qulvre el motectimiento jor el ploems y ei furgo de puebles, y tarks y milloside de hijos Lel yuebla hombers, wayeres y allos, ras a eer exterminados en wask, es los frentes de batalla, en las dodadea $y$ los campos de Afri. ca. Los ariosen del dictabor, a Menejosea de belites carniceros que merobias al olor de diasdo eladabes enteras; ofrecleada an al

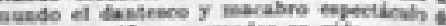
asjeres $Y$ alfos, vuemados te vila. Cafa bork. el cable nes diee qae la tobar.

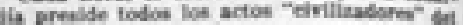

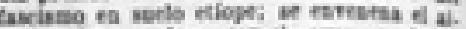

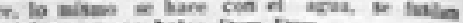

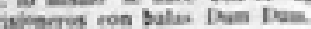

\section{scrstei postcios}

Despoh de varias reunleses brase toen. citalibo ef Ceailte de fa Rasa Negra vootn is Goern y el Fasiamo

Soutesenina ged la primer victima is is

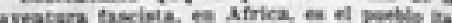

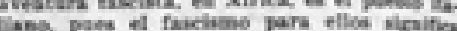

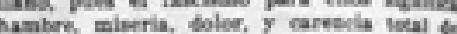
tibertades $y$ is goerra, dermananievis of ws.

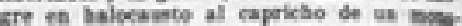

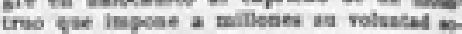
berank.

In tal sentido cosilderamos even massa

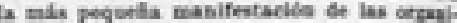

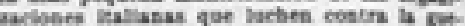
wa $y$ el factima.

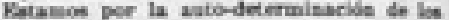
patblos, por ef berecho a coberzarse in of mismo: estesdetwos gae of tanciras trouch

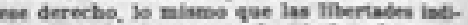
rifuales, slesbo un earmipo de la culturn. W arte. Ia ciencia apeovechands de exla it tima who bo que tiene relacion con la grems

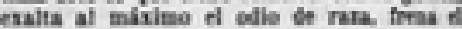

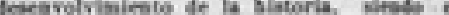
peor pelizero para ia bamanidad. Fee bo wa ta. witanos dispuestos a jecstar apore i $t$

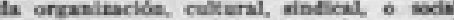
que traga cemo finalidad, is locka ecotra ol hacismo $y$ is govrra.

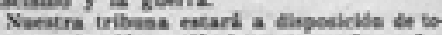
da organimarkle antifactsta que en feerwa to. tertal auiera miablecet canye de orharis. a a ver que recla mamoe el apoyo de todion is abrerua of los inteintrales blascos. of

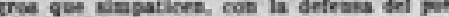
Slo briope $y$ la locha coetra la gowm $y$ ti tascismo.

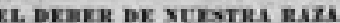

Por las rasoses exporikas sarith organ-

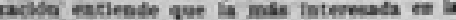

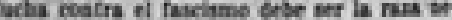

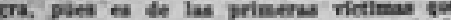

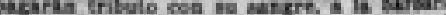

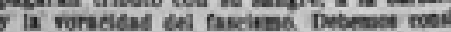

Texto del Manifiesto del Comité de la Raza Negra

contra la guerra y el Fascismo. 24 de noviembre

de 1935, año III, número 28, págs. 8-9. 


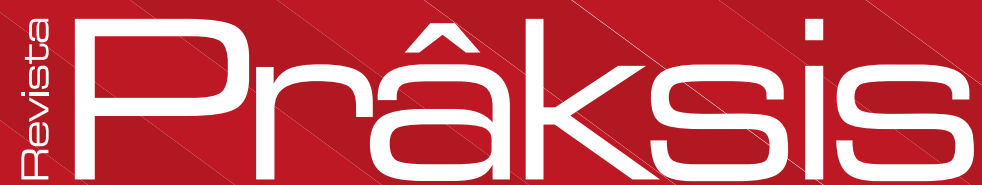

p-ISSN: 1807-1112

e-ISSN: 2448-1939

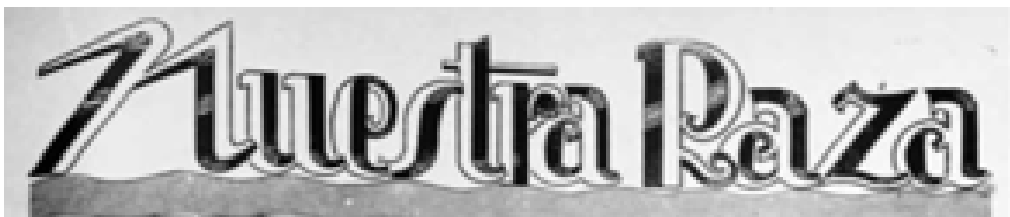

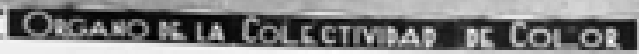

Moutevileo, Dicirmbere 24 de 1905

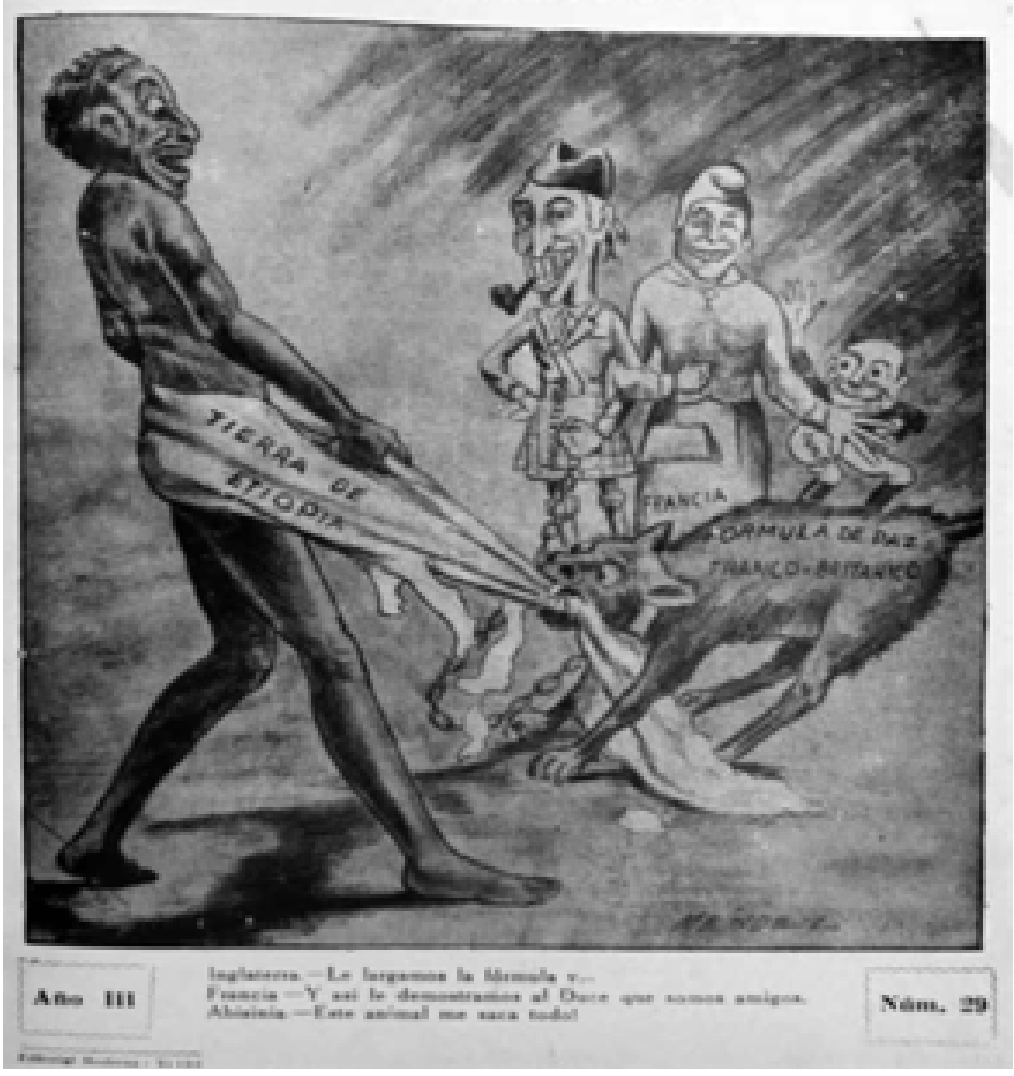

24 de diciembre de 1935, año III, número 29 


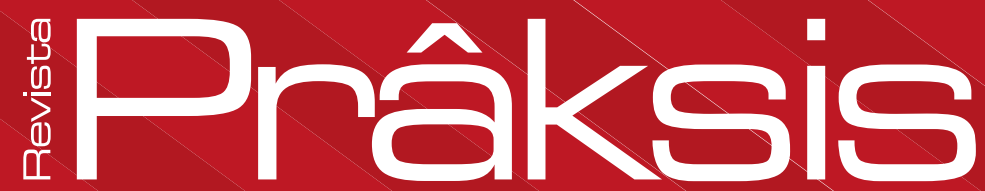

p-ISSN: 1807-1112

e-ISSN: 2448-1939

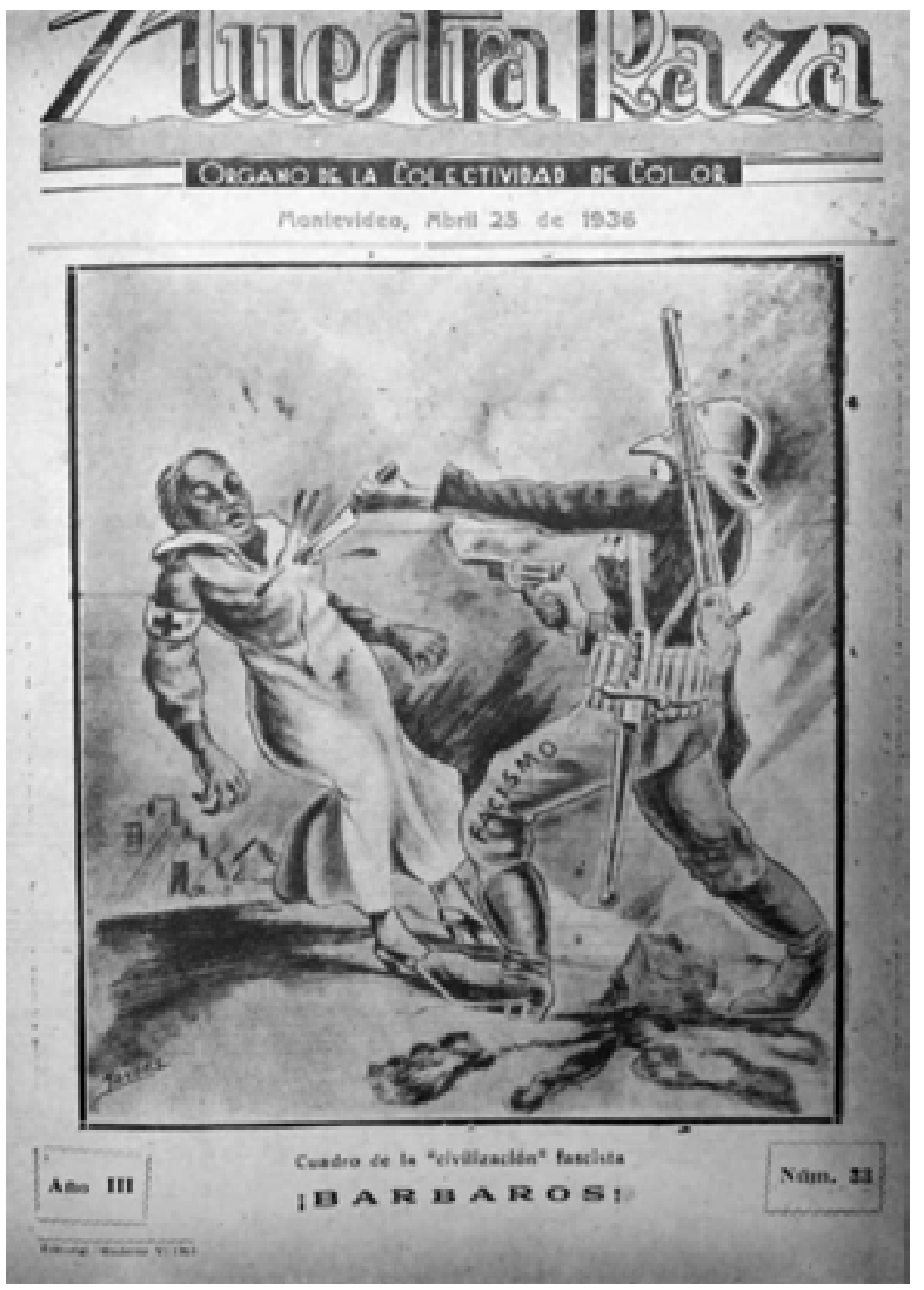

25 de abril de 1936, año III, número 33 


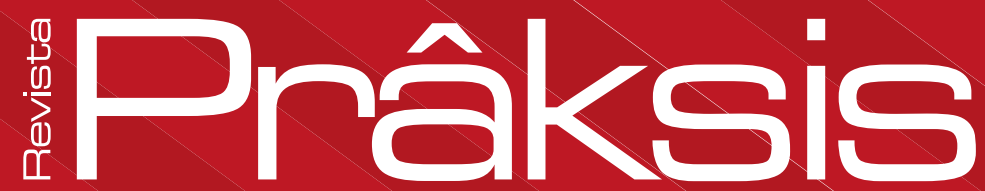

p-ISSN: 1807-1112

e-ISSN: 2448-1939

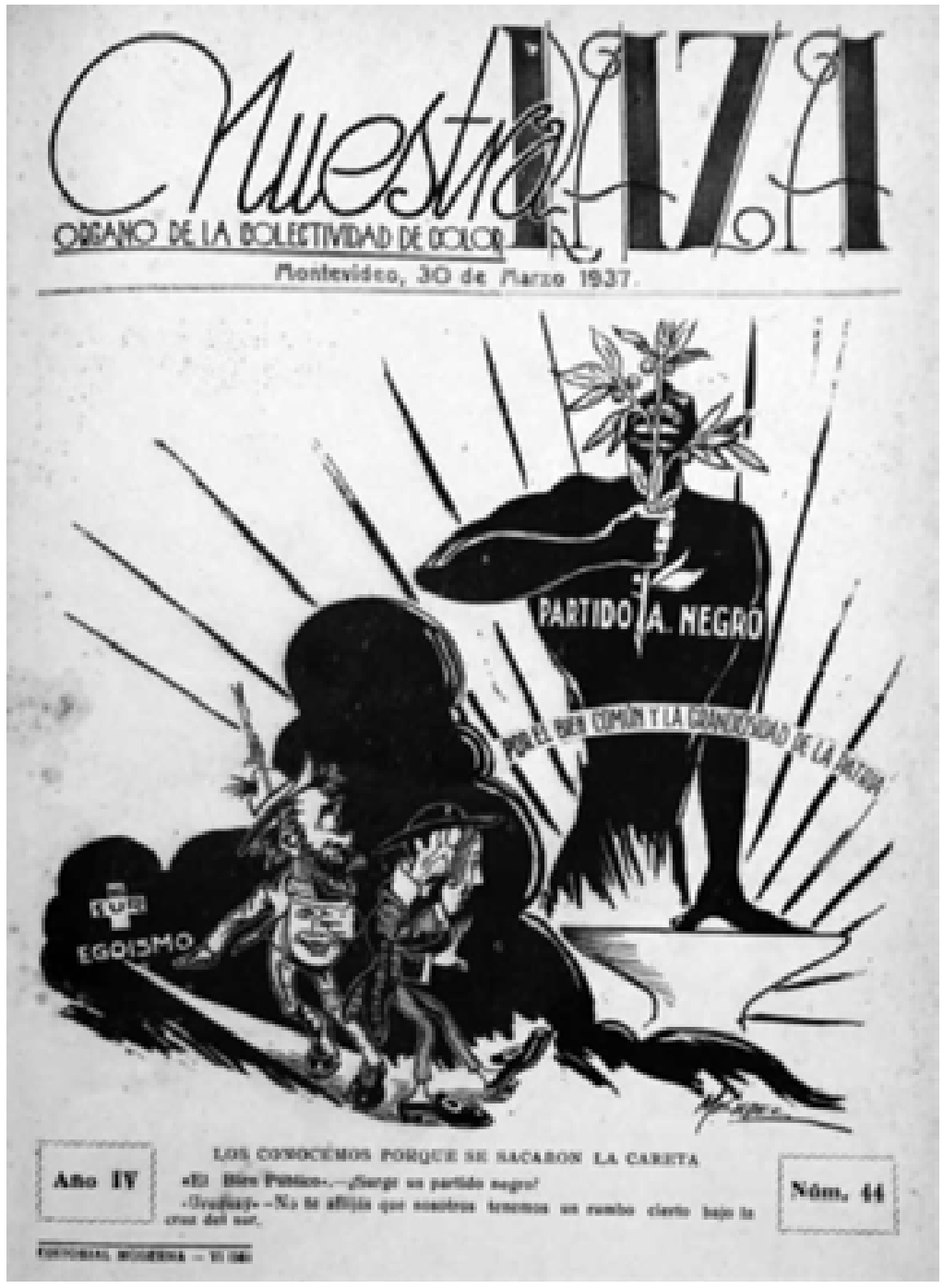

30 de marzo de 1937, año IV, número 44 


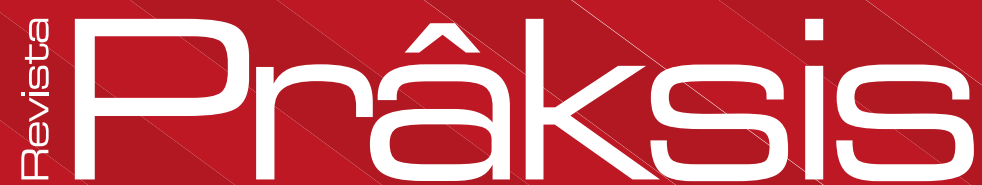

p-ISSN: 1807-1112

e-ISSN: 2448-1939

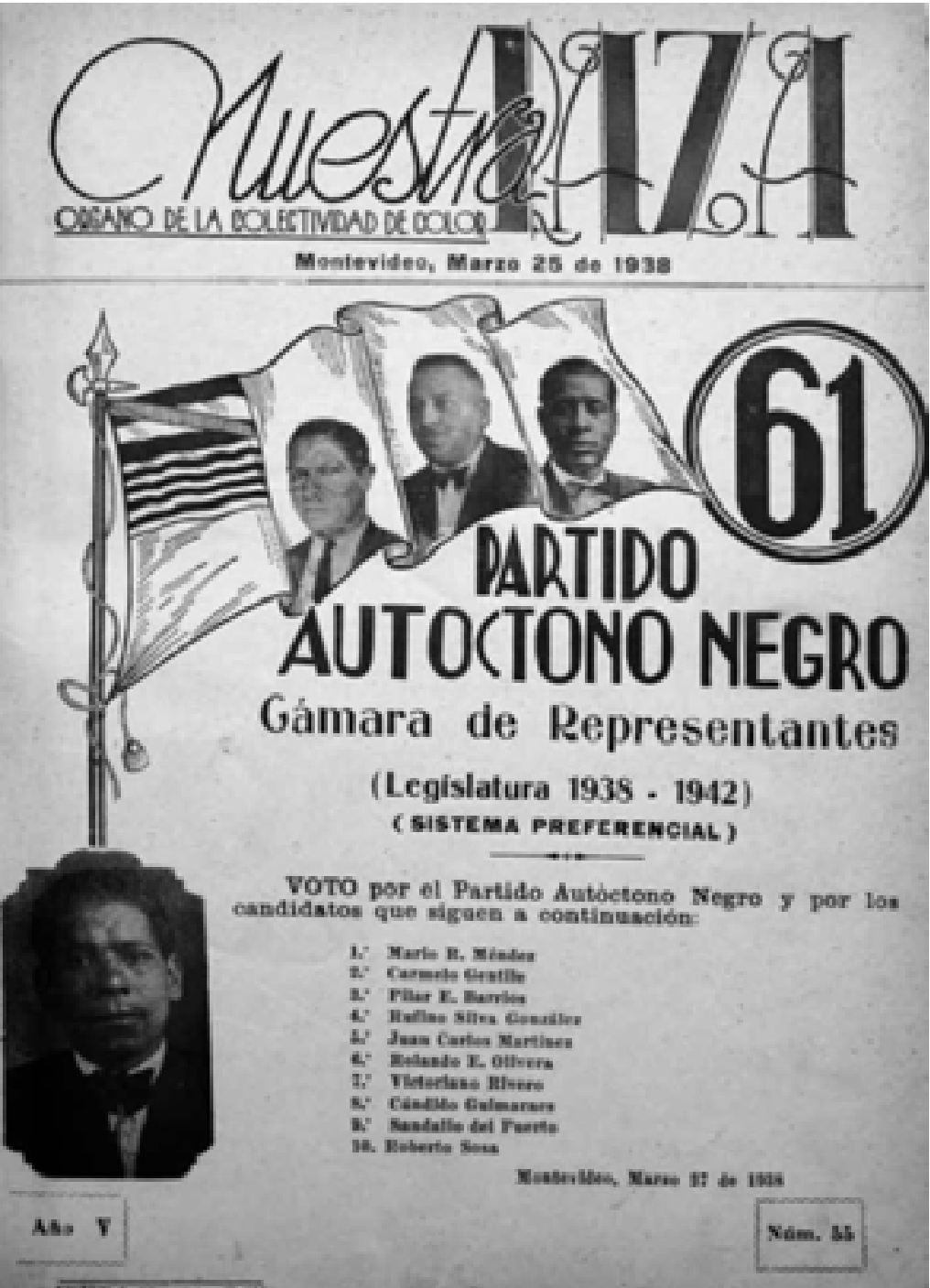

Lista del Partido Autóctono Negro donde aparece

Méndez en la foto del centro de la bandera. 25

de marzo de 1938, año V, número 55, pág. 69. 